\title{
Editorials
}

"Medicine, like all knowledge, has a past as well as a present and a future, and ... in that past is the indespensable soil out of which improvement must grow."

Alfred Stille

Medical News 1884;44:433.

The Perinatal Section of the American Academy of Pediatrics celebrated its 25th Anniversary with a celebration in Washington, DC. As part of the program, the creation and early years of our development was presented by George Little. The history of the 1980's and 1990's was reviewed by Bill Keenan, and thoughts of the future were philosophically described by David Stevenson. We are creatures of the past, and it is important to understand the past to predict the future. Therefore, it is fitting that the "Editorial" page of the Journal of Perinatology belongs to the History of the Perinatal Section of the American Academy of Pediatrics.

\author{
Gilbert I. Martin, MD \\ Editor-in-Chief
}

\section{The Perinatal History of the Section on Perinatal Pediatrics}

\section{George A. Little, MD}

The birth of the Section on Perinatal Pediatrics of the American Academy of Pediatrics (AAP) occurred in October of 1974. Although the body giving birth was the Executive Board of the AAP, there was a large extended family including individual fellows, the Committee on the Fetus and Newborn (COFN), and state chapters. The family, like many, was diverse and complex, as evidenced by the fact that it supported and promoted the emergence of a new member while within the family circle and behind closed doors healthy challenge and debate took place.

\section{COURTSHIP}

In the 1960s and on into the early 1970s, perinatal science was advancing rapidly; in addition, neonatal intensive care was being implemented in hospitals and regionalization was being discussed. The annual neonatal dinner at the spring meetings in Atlantic City progressed to involve more than one table. The network was in place.

Many participants in the growing network can be mentioned, among them Apgar, Avery, Battaglia, Gluck, James, Korones, Lubchenco, Lucey, Seagal, Silverman, Smith, Stahlman, Tooley, and Usher. A review of papers and recollections reveals clearly that one individual, L. Joseph Butterfield, was beginning his long commitment to newborns and his dedication, almost obsession, with Section affairs. L. J. B. was in pursuit of his vision.

Children's Hospital at Dartmouth, Dartmouth-Hitchcock Medical Center, Lebanon, NH. Address correspondence and reprint requests to George A. Little, MD, Children's Hospital at Dartmouth, Dartmouth-Hitchcock Medical Center, Lebanon, NH 03756.

\section{PRECONCEPTION}

In April of 1972, the Colorado Chapter of the AAP passed a resolution that a Perinatal Pediatrics Section should be formed. In October, the executive board deferred action due to concern about need and qualifications. Preconception care was passed to a $\mathrm{COFN}$ subcommittee of Drs. Tooley, Segal, and Graven, who were charged to prepare a study document.

\section{CONCEPTION}

In June of 1973, the AAP Executive Board passed a motion that "a Section on Perinatal Medicine be approved in principle."1 The COFN subcommittee had recommended in April that a section be developed, that "nurses with special training" be able to participate, and that obstetricians be affiliate members. The Advisory Committee of the Board on Committees recommended that COFN prepare bylaws and guidelines.

\section{GESTATION}

The growth and development of the fetal section progressed through the first 9 months of 1974. In June of 1974, the Executive Board referred proposed bylaws with two types of membership, regular and associate, back to the COFN. In July, COFN recommended that membership be open to all AAP fellows without restriction to those certified in a subspecialty, while recognizing that some other sections did restrict membership on the basis of boards.

Termination of the gestation was avoided when the Executive Board in June did not take action on a chapter resolution that the AAP withdraw approval of a subspecialty board and section. 


\section{BIRTH, NEONATAL PERIOD, AND INFANCY}

The corpus delivered by decision of the AAP Executive Committee in October of 1974 included approved revised bylaws and an appointed first section committee of: William Tooley, chair and designated Far West, Jacob Kay (Rockies-Southwest), George Cassady (South), Jim Sutherland (Mid-West), Lois Neumann (Mid-East), and George Little (Northeast).

Organizing meetings of the section committee at the annual meeting in San Francisco included discussion of mission, establishment of presence, breadth of membership beyond pediatricians, and activities including programs and awards. The committee deferred decisions concerning wines to the wisdom and reputation of the chair.

The executive board in April 1975 approved the revision of bylaws and deferred approval of guidelines for the Apgar Award, with approval coming at its June meeting. In July, an announcement appeared in Pediatrics ${ }^{2}$ declaring executive committee approval the previous fall, listing committee members, and stating that membership was to be open to all members of the Academy with a special interest in perinatal pediatrics. Fellows wishing to join were invited to request an application to be submitted with two letters of recommendation. The requirement for letters was soon dropped.

In October, during the annual meeting of the Academy in Washington, the first business and scientific sessions took place and Clement Smith received the inaugural Apgar award.

\section{INFANCY}

The 1976 section committee devoted considerable time to learning and defining its environment and interactions. A June letter to the executive board recommended AAP district sections, district education programs in conjunction with the nursing profession and American College of Obstetricians and Gynecologists, profit sharing between national and district sections, section participation in COFN, and publication of a quarterly newsletter. The board appointed an ad hoc committee that included members from the Section, COFN, and Committee on Medical Education for further study of controversial parts of the recommendations.

\section{EARLY CHILDHOOD}

In November of 1976, a joint Section/COFN statement generated in large part by Stan James of COFN and Bill Tooley and Jim Sutherland of the Section was sent to the executive board. According to this agreement, the Section was responsible for educational activities including surveys, a newsletter, one or two national postgraduate courses, periodic symposia held under the auspices of state chapters and district sections, and advocacy. COFN's role as a technical advisory and expert group was acknowledged, with responsibilities to include advising the board on specific issues in perinatal health and periodic revision of Standards and Recommendations for Hospital Care of Newborn Infants.*

Of special note is the fact that research was not mentioned in the communications of the time, nor was there much discussion that I recall. Computer databases of clinical data and listings of personnel and services were in their early stages of organization and use for independent study.

The advisory committee of the Board on Committees reviewed and generally supported the statement defining the relationship of COFN and the Section, and the statement was finalized in June of 1977. The Section chair and secretary were designated consultants to the COFN. The first issue of the newsletter appeared in March of 1977.

Early Section educational activities took place at the AAP annual meeting and in Districts V and VIII in 1976. In 1978, a postgraduate course was undertaken with the Academy chapter in Florida, and in 1979 a course was given in the Virgin Islands, where an ocean liner burning in Charlotte Amalie harbor provided special entertainment for participants. The publication of the first edition of Guidelines for Perinatal Care in 1983 took place after years of preparation and review that included participation of the Section committee.

\section{Acknowledgments}

We thank John Zwicky, PhD, Archivist at the Pediatric History Center, American Academy of Pediatrics (Elk Grove Village, IL) for assistance.

\section{References}

1. Minutes, Executive Board Meeting. Elk Grove Village, IL: American Academy of Pediatrics; June 28-30, 1973.

2. Announcement. Pediatrics 1975;56:156.
*After multiple editions, Standards and Recommendations for Hospital Care of Newborn Infants was integrated into Guidelines for Perinatal Care, which is published jointly by AAP and American College of Obstetricians and Gynecologists. 


\section{Section on Perinatal Pediatrics: The 1980s to the 1990s}

\section{William Keenan, MD}

The beginning of the 1980s was a quiet one for the Section. The annual educational program and the Apgar Award were set. Membership was static, and the Section had not yet become project oriented. George Peckham, as the chair of the Section, was expending considerable energy to move the American Academy of Pediatrics and the American Heart Association to consider a major educational investment in neonatal resuscitation. To meet expanding educational needs, the Section held additional spring sessions during 1987 in St. Louis and in San Diego; these were the form fruste for what was to become the Section's spring session, now held annually in Arizona. Joe Butterfield and Bill Keenan concentrated their efforts on contacting the neonatology community and asking them to consider using the Section as their home base for organizational and educational activities. Luann Papile helped establish an American Academy of Pediatrics district level grant system to stimulate multiple regional perinatal conferences and organization. Luann was also instrumental in adding a competitively selected scientific session to the fall educational program. This helped involve more trainees and faculty. With the Section committee's enthusiastic support, Joe initiated his campaign for the generation of a United States stamp honoring Virginia Apgar. The neonatal dinner held for many years during the American Pediatric Society/Society for Pediatric Research meeting evolved into a Section-sponsored Neonatal Gathering with the help of Dewey Sehring. The Section newsletter started by Joe Brazie came under the editorship of Jeff Gould and became a robust regular publication full of news for the neonatal community. Section representatives met with the March of Dimes and helped launch the second edition of Toward the Improvement of the Outcome of Pregnancy under the direction of George Little.

During this time, the American Academy of Pediatrics support structure for Sections began to evolve. Ken Slaw helped establish the first budgeting process and was very helpful when he served as the first staff person for the Section.

Later in the 1980s, membership increased; an affiliate membership envisioned by the original founding group also began to grow, with attempts to establish formal liaison relationships with the nursing organizations. Attention was given to the expanding neonatology membership whose practices were not in academic centers. Greg Lund, Lou Pollack, and David Wells were especially influential in establishing the Committee on Practice to ensure the representation of the practicing neonatologist. As the Section activities grew, John Driscoll had the idea of enlarging the

St. Louis University School of Medicine, St. Louis, MO.

Address correspondence and reprint requests to William J. Keenan, MD, St. Louis University School of Medicine, 1465 South Grand Boulevard, St. Louis, MO 63104.
Section committee representation to ensure that each American Academy of Pediatrics district was represented.

The Section became the sponsoring group establishing the Neonatal Resuscitation Program, which relied on the text created by Cathy Cropley and Ron Bloom. This program helped formalize instruction in neonatal resuscitation for a wide constituency around the world. As last count, 1,250,000 professionals had participated in this program in the United States alone.

Two educational projects were initiated in the 1980s. Siva Subramanian had hosted several informal meetings of neonatal fellowship directors to discuss common challenges and potential solutions. Bob Cotton and Bob Hall helped formalize this meeting under the auspices of the Section and created a set of bylaws; this group then became the Organization of Neonatology Training Program Directors, which now meets annually to discuss improvements in neonatal education for pediatric residents and fellows. The Section committee representatives felt that a more formal and more intensive review for neonatologists and fellows was necessary. Under the leadership of Bob Perelman, the first of a five and a half day NeoPREP course was held in St. Louis in 1988 and has been offered every other year since that time.

The activities of the Section of Perinatal Pediatrics in the 1990s continued to be brisk. The Neonatal Resuscitation Program with American Heart Association participation continued as an educational program with worldwide participation and official translation of the text into 14 additional languages. The Organization of Neonatology Training Program Directors is now the major organizing point for considerations in graduate neonatal education.

The Thomas Cohen Lecture, which was first established in 1993, historical interviews with leaders in perinatal care regularly published in the Perinatal News, and a subcommittee developing information on the historical roots of infant care are flourishing endeavors. The Neonatal Education Award was established in 1996 to recognize outstanding individual contributions to perinatal education. The 1999 awardee was Avroy Fanaroff. The Journal of Perinatology, with Gil Martin as Editor-in-Chief, is now the official publication of the Section on Perinatal Pediatrics. A new electronic journal, Neo Reviews, was established by the Section, with David Stevenson and Bill Hay as co-editors.

The annual spring session has evolved to a lively forum on regionalization, practice, manpower, and managed care, as well as managed care with a competitive selected poster section. The $\mathrm{L}$. Joseph Butterfield Lectureship was established by the Section in 1997.

Under Rich Molteni's energetic tutelage, the Section has established a relationship with the Health Care Finance Administration and has set up a team of coding trainers to assist neonatologists all over the country in 
dealing with the demanding changes of modern reimbursement.

The first 25 years of the Section on Perinatal Pediatrics have contributed immensely to education, research, and professional cooperation in perinatal medicine. These first 25 years have been fueled by dedication, hard work, imagination, and openness to the possibilities in others. We feel that the same qualities among the neonatology community will power an equally productive next 25 years.

\section{On the 25th Anniversary of the Section on Perinatal Pediatrics: Historical Foresight}

\section{David K. Stevenson, MD}

What I have been asked to provide is a kind of look into the future of the Section on Perinatal Pediatrics, having some sense of where it has been and where it is now. This concept of "historical foresight" has been addressed before by a philosopher named Alfred North Whitehead in a book entitled Adventures of Ideas, ${ }^{1}$ in which he explores the concept using the example of commerce in civilization. I am tempted also to comment on commerce in medicine, but I will refrain from doing so in mixed company, and I cannot do critical justice to Whitehead's book or the larger philosophical issues that he considers in it. My commentary must be brief, and it is only my vague recollection of Whitehead's text that has influenced my assumption of this project.

My task seems not to be served by simple scientific induction, moving from particular facts about our past and present, described before by my colleagues, to some general conclusion about the future. Indeed, the future conceived as a generality might apply to any course one might envision, but could not determine one particular course from another. Theoretically, if I knew all the relevant rules that govern Sections in the American Academy of Pediatrics and the detailed facts, past and present, of our particular Section, I should be capable of prediction, much as in astronomy, although the latter deals with relatively simple circumstances compared with perinatal pediatrics. The seriousness of my disability in prediction is evidenced by my ignorance of the future of most things, even those intimate ones, such as the domestic details of my life tomorrow or ultimately of the term of my own existence. Yet, I am inclined toward forecasting, the same way one is allured by the endlessly updated reports on the Weather Channel. If only a 5-day forecast were sufficient, I could spend most of my time discussing why yesterday's predictions had not adequately described today.

Forecasting is a way of taking stock of one's current disposition in view of the past, because it is the predisposition for whatever circumstances are going to pertain in the future. As Whitehead suggested, historical foresight has two sources of difficulty: one could be called scientific (in our case, a seeking of the general rules that govern the organization and operation of Sections); the other is an "emphasis on the relevant facts from which

Department of Pediatrics, Division of Neonatology, Stanford University School of Medicine, Stanford, $C A$.

Address correspondence and reprint requests to David Stevenson, MD, Department of Pediatrics, Division of Neonatology, Stanford University School of Medicine, Stanford, CA 94304. the future is to emerge" for our particular Section. The former seems feasible, that I might actually grasp how the American Academy of Pediatrics rules its Sections, but the latter causes me to hesitate at the verge of tomorrow. What facts should I gather from our Section's past and present to make my prediction? Whitehead's choice of commercial relations as the field "to illustrate the function of ideas in the provision of anticipation and purpose" does not assist me further in my particular project. However, I would agree with him that it would be best that one who practices in the field should make the prediction; in that regard, I do qualify.

The character of the Section is determined by the way in which it reacts to the material events that it encounters. This reaction is determined by beliefs, such as what is worthwhile, and what is worthwhile I can say with confidence is to improve the care and outcomes of care for babies, their mothers and fathers, their families, and to educate those of us who inhabit the Section to do this as well as we can. In my clarification of this belief in what is worthwhile, I have fulfilled in part my role as philosopher and soothsayer and determined the emphasis of our future attention: the future is on the path that we are now on, well-traveled for 25 years, with more and more of us coming along together, sharing the same sense of purpose. We are the entryway to the rest of Pediatrics. As we shift our outlooks, and with them our practices, we change the very routes that individual lives, patients and professionals, will follow.

What is our future? It is in the direction of our beliefs and is informed by our continuing education. No doubt, we will have better tools for our educational purpose. An electronic virtual world will provide us with access to knowledge, content, and applications, including simulated experiences. There will be great scientific and technical advances that will allow us to explore biology in ways that we now are only imagining, manipulate it to a specified consequence, and understand that, despite our gaining omniscience and omnipotence, we will remain fundamentally creatures of context, in part fabricated and in part inherited. Our practices will be increasingly evidence-based and our approaches preventive. We will reduce environmental hazards and iatrogenesis. We will measure our outcomes in terms of human performance, and technical accomplishments will be complemented routinely by ethical ones. In the future, however, we will return 
again and again to the babies. They are the attraction and the mystery that allures each of us. They literally embody our future.

What is the future? It is ahead of us to be sure. It is ours to be sure. It has no ending. The coming and going will go on forever. Gabriel Garcia-Marquez said it more powerfully and beautifully at the end of Love in the Time of Cholera, ${ }^{2}$ through the words of the captain: "'and how long do you think we can keep up this God damned coming and going?' he asked. Florentino Ariza had kept his answer ready for 53 years, 7 months, and 11 days and nights.
'Forever,' he said." “. . . life, more than death. . . has no limits." And so the Section, with the emphasis of our attention on the beginning of life, is like the captain's boat, capable of navigating the waters forever.

\section{References}

1. Whitehead, AN. Adventures of Ideas. New York: The Free Press; 1967.

2. Garcia-Marquez, G. Love in the Time of Cholera. New York: Alfred A. Knopf; 1988. 